\title{
AS PERCEPÇÕES HUMANAS, SEGUNDO DAVID HUME
}

\author{
Autor: Marcelo de Sousa Ferreira Alves ${ }^{1}$ \\ I
}

René Descartes nos diz em seu livro Regras Para Direção do Espirito, especificamente na regra XII, que: "No que concerne o conhecimento, só é preciso levar-se em consideração duas coisas: nós, que conhecemos, e os objetos que devem ser conhecidos." (DESCARTES, 2010, P. 443.) O conhecimento segundo Descartes se dá nesta relação de dualidade sujeitoobjeto. Contudo, Hume vê essa relação problemática, pois não temos o objeto. $O$ "objeto" já é dado na percepção, no perceber, então para Hume não há objeto², mas sim percepção. Não há uma distinção do objeto e de como percebemos o objeto, já que ele (o objeto) já aparece na mente, é percepção. Esta negação de uma dualidade no conhecimento é uma proposta não de Hume mas do filósofo George Berkeley, Hume adota sua tese principal Ser é ser percebido3, pois por percepção Hume entende "qualquer coisa presente no espirito" (HUME, 1975, P.30). Portanto, no início do primeiro capítulo de seu Tratado da Natureza Humana, já está como que pressuposto uma leitura da obra Tratado Sobre os Princípios do Conhecimento Humano de Berkeley. Smith, embora não citando Berkeley, evidencia esse pressuposto em sua obra O Ceticismo de Hume:

\begin{abstract}
Evidencia-se aqui uma herança histórica de Hume não questionada. $A$ teoria dos dados dos sentidos ou de que a mente só tem acesso a percepção, não a coisas, é aceita por Hume. (...) A nada, portanto, a mente tem acesso, senão a percepções, estando confinada a si mesma. (SMITH, 1995, p49)
\end{abstract}

A despeito disso, é mister destacar, contudo, que Hume estabelece uma divisão entre as percepções humanas que se afasta da perspectiva de Berkeley. Quando perguntamos: de onde vem nossas percepções, uma vez que não há um objeto do qual elas derivem? Hume, diferentemente de Berkeley que atribui nossas percepções a Deus, nos responde que "nascem originalmente da alma, de causas desconhecidas" (HUME, 2000, P. 32.) portanto, mostrando o caráter

\footnotetext{
1 Graduado e Mestre em filosofia pela UFC (Universidade Federal do Ceará).

${ }^{2}$ Objeto aqui entendido como algo fora ou separado do perceber, ou seja, fora das percepções da mente.

${ }^{3}$ Hume adota esse princípio enquanto percepção, sem suas distinções de percepções.
} 
inato ${ }^{4}$ das percepções. Como percebeu André Verger: “(...) não seria correto supor que, para Hume, o espirito fosse meramente passivo, uma tábua rasa, uma massa mole onde se inscreveriam mecanicamente os estímulos externos." (VERGER, 1984, p. 18). O espirito não é passivo em Hume porque ele constrói as ideais complexas, que são, segundo o autor, “(...) os objetos comuns de nossos pensamentos e raciocínios (...)" (HUME, 2000, p.37), como veremos a seguir. Desta forma, tomando as percepções da mente como inatas, resta a Hume iniciar sua Teoria do Conhecimento não como Descartes, falando sobre a relação sujeito e objeto, mas sim falando sobre as percepções da mente, que são a totalidade dos fatos mentais, dados originários da consciência, ou nas palavras do próprio autor: "todos os materiais do pensamento".

Considerado o terceiro da tríade empirista inglesa, Hume, diferentemente de seus predecessores que viam na ideia tudo que constitui o conteúdo da consciência, opera uma distinção importante dos demais. Locke diz já na introdução de seu Ensaio Sobre o Entendimento Humano, ser a ideia:

\begin{abstract}
(...) o termo que, a meu ver, melhor designa tudo o que possa ser objeto do entendimento quando um homem pensa, com ele significarei o que pode ser expresso com a palavra fantasma, noção, espécie, ou o que quer que o espirito utilize para pensar. (LOCKE, 2010, 27).
\end{abstract}

Berkeley, um crítico voraz de Locke, vai mais longe e diz que só temos acesso as ideias, já que não há objetos externos: "Quando nos empenhamos ao máximo para conceber a existência de corpos externos, estamos o tempo todo somente contemplando nossas ideias" (BERKELEY, 2010, p. 72).

Hume, divergindo de Locke e Berkeley, divide os objetos do entendimento ou as percepções humanas em duas, pelo seu grau de força e de vivacidade, uma ele chama de impressão e a outra de ideia. A rigor, essa divisão não presume uma dicotomia, nem estabelece entre seus termos diferenças antagônicas de natureza, com essa divisão o que Hume pretende propor é a limitação de todo o material do pensamento às percepções. As impressões são as percepções vivas, ou seja, quando estou tendo o contato imediato com o que

\footnotetext{
${ }^{4} \mathrm{O}$ inato aqui não é entendido como nascer com, mas sim a pura aparição na alma de percepções sem uma causa.
} 
percebo, como, por exemplo: quando olhamos uma cor, ou quando estamos emocionados. Já as ideias são pálidas imagens derivadas das impressões, ou seja, são cópias de impressões, como, por exemplo: quando tenho a lembrança ou quando antecipo a aparição (depois de já ter tido a experiência) de uma impressão em minha mente. Naturalmente uma coisa é alguém estar se queimando e outra quando esse mesmo alguém lembra de tal momento. Segundo Hume, podem existir momentos nos quais nossas ideias se aproximam de nossas impressões, como no caso do sono, da loucura ou de um delírio febril; e também pode acontecer o oposto, quando nossas impressões são tão apagadas e fracas que não conseguimos distingui-las de nossas ideias, mas, embora isso: "O pensamento mais vivo é sempre inferior à sensação mais embaçada" (HUME, IEH 1999, p. 35). Limitar as percepções mentais à impressão e à ideia é o mesmo que dizer que todo o conteúdo mental é uma imagem ou uma sensação.

A ideia é cópia da impressão e a impressão é nascida da própria natureza humana sendo inata ${ }^{5}$ :

Porque é evidente que nossas percepções mais fortes, ou impressões, são inatas, do mesmo modo que o afeto natural, o amor da virtude, o ressentimento; em suma, tanto estas como as outras paixões nascidas imediatamente da natureza [humana] (HUME, 1975, P.31).

Quanto às impressões provenientes dos sentidos, sua causa última é, em minha opinião, inteiramente inexplicável pela razão humana, e será para sempre impossível decidir com certeza se elas surgem imediatamente do objeto, se são produzidas pelo poder criativo da mente, ou ainda se derivam do autor de nosso ser (HUME, 2000, p.113).

A cópia é a relação que se tem entre as percepções (impressões e ideias), mas tal cópia se manifesta de três maneiras, a saber: por semelhança,

\footnotetext{
${ }^{5}$ Cabe aqui uma importante ressalva. Quando Hume diz que as impressões são inatas o inato dito por ele não se assemelha em nada com concepções platônicas, cartesianas ou leibnizianas, não tem absolutamente nenhum grau de parentesco com reminiscência, muito pelo contrário, o conceito de inato falado por Hume é o mesmo proposto por Berkeley, ou seja, se não há mais uma relação de dualidade (sujeito-objeto) no conhecimento, toda e qualquer percepção se torna inata, na medida que ela não deriva de nada exterior. E o próprio Hume, por essa concepção, constata essa evidência: "Porque é evidente que nossas percepções mais fortes, ou impressões, são inatas" (HUME, 1975, p. 31). Ao contrário de muitas posturas que os muitos manuais de filosofia assumem acerca de Hume, Hume tem em sua filosofia o inato como uma característica da própria constituição dos dados originários da consciência, quando Hume afirma que todo conhecimento começa com a experiência, ele não entende experiência como Locke entende (uma relação sujeito-objeto), por experiência Hume entende a pura aparição da ideia na mente e também relações mentais no processo de criação de ideias complexas, como ficará exposto nos capítulos seguintes.
} 
contiguidade e causalidade. ${ }^{6}$ Nossas percepções aparecem como semelhantes, ou seja, os dados das impressões são os mesmos das ideias (a impressão que tenho da cor amarela assemelha-se com a ideia da mesma), da mesma forma se manifestam como cópias:

A primeira circunstância que me chama atenção é a grande semelhança entre nossas impressões e ideias em todos os pontos, exceto em seus graus de força e de vividez. As ideias parecem ser de alguma forma os reflexos das impressões; de modo que todas as percepções da mente são duplas, aparecendo como impressões e como ideias. (HUME, $T N H, 2000$, p 26-27)

Também aparecem-nos contíguos: pois as percepções semelhantes se mostram por conjunções (ao termos a impressão de amarelo contiguamente temos a ideia do mesmo).

Dessa conjunção constante de percepções semelhantes, concluo imediatamente que há uma forte conexão entre nossas impressões e ideias correspondentes, e que a existência de umas tem uma influência considerável sobre as outras. (HUME, TNH, 2000, p28)

E por último causal, sendo uma dependente da outra (sem a impressão da cor amarela não teríamos a sua ideia). Fica-nos claro nestas citações:

A conjunção constante de nossas percepções semelhantes é a prova convincente de que umas são causas das outras; e essa anterioridade das impressões é uma prova equivalente de que nossas impressões são as causas de nossas ideias, e não nossas ideias causa de nossas impressões. (HUME, 2000, TNH, p 29)

O que mais me chama atenção é que Hume evoca os princípios de associação de ideias (semelhança, contiguidade e causalidade), que só serão devidamente explicados em tópicos posteriores, para explicar ou justificar a relação entre as percepções. Isso irá fazer com que Hume caia em uma série de problemas que veremos no decorrer do texto.

Antes de continuar a falar das relações entre as percepções, cabe aqui falar sobre uma divisão nas impressões feita por Hume. As impressões se dividem em impressões de sensação e em impressões de reflexão. As

\footnotetext{
${ }^{6}$ Aqui Hume evoca os princípios de associação de ideias sem ter devidamente os explicado, onde o fará posteriormente. Esses princípios serão melhor entendidos no próximo subtítulo.
} 
impressões de sensação são aquelas que tocam os sentidos, como frio, calor, dor e etc. Já as de reflexão são os desejos ou aversão, esperança ou medo e etc. As impressões de reflexão são originadas, ou melhor, são derivadas de nossas ideias, como uma espécie de cooperação entre ambas (impressões de sensação e as ideias delas advinda) dando origem a impressão de reflexão, como, por exemplo, quando tenho a impressão de sensação de frio e, concomitantemente, surge à ideia do mesmo, logo nasce uma outra impressão da ideia de frio que é de reflexão acerca de desejá-la ou repudia-la. Desta forma, quando temos uma impressão de sensação, logo temos uma ideia correspondente que traz consigo outra impressão, que é chamada de impressão de reflexão, e que, por sua vez, também traz, ao mesmo tempo, outra ideia que poderíamos simplesmente chamar de ideia de reflexão, embora Hume não tenha mencionado tal termo.

Depois de mostrar as relações (semelhança, contiguidade e causalidade) entre as percepções, Hume mostra que tais relações não são necessárias, ou seja, elas podem não corresponder. Uma ideia pode não ser uma cópia (ou uma cópia exata) de uma impressão. A ideia de um cavalo-alado, uma montanha de ouro ou de uma sereia, por exemplo, não são copias de impressões correspondentes. Embora não sejam cópias, derivaram de impressões, dirá Hume, como, por exemplo, de um cavalo e de uma asa (como no caso do cavaloalado). Para explicar como se dá essa "incorrespondência" entre as percepções Hume propõe mais uma subdivisão que talvez seja até mais importante que a primeira divisão, não só para o trabalho aqui pretendido, mas para toda sua filosofia, aplicada tanto as impressões quanto as ideias, que são: percepções simples e complexas?. Percepções simples são aquelas que não se dividem e nem se distinguem em partes, como no caso de uma cor, um cheiro, um som e etc. Ao contrário das simples, as complexas se dão por junções de simples, como

\footnotetext{
${ }^{7}$ Falar de percepções complexas voltada apenas as impressões complexas em Hume é bastante problemático. Hume dificilmente cita as impressões complexas, e na maioria de seu Tratado ele só se refere às ideias complexas. Eu parto de uma leitura de uma passagem do tratado que diz: "muitas de nossas ideias complexas jamais tiveram impressões que lhe correspondessem" (2000, $T N H, \mathrm{p} 27)$. Nesta passagem nosso autor deixa espaço para entendermos que há impressões complexas que se correspondem com ideias complexas, mas o porquê que ele só se refere posteriormente às ideias complexas, o mais provável é que como, em última instancia, não há uma dicotomia entre as percepções, eu posso falar de uma que me remeterei a outra. No delinear do texto irei optar sempre me referir, quando falar em complexo, a percepções complexas (que é tanto impressões como ideias), já que a distinção, embora fraca, é o grau de força e vivacidade, se eu falar de ideias (sem se remeter a distinção de força e vivacidade) estarei falando das impressões. Falarei no próximo subtítulo, um pouco mais afrente, sobre essas percepções quando me referir a memória e a imaginação.

${ }^{22}$ Itálico do próprio Hume.
} 
no caso da maçã, que é uma junção de cor, cheiro e gosto. As percepções complexas são de dois tipos, regulares e fictícias. Quando há uma regularidade há uma correspondência entre impressões e ideias, como no caso da maçã citada anteriormente. Quando não há uma regularidade ela é fictícia, criada pela imaginação e não havendo correspondência entre as percepções. Sendo assim, complexa fictícia se torna uma característica apenas da percepção ideia.

Como as correspondências no âmbito das percepções complexas são problemáticas, Hume resolve se limitar a correspondência de percepções simples afirmando que "todas as ideias simples, em sua primeira aparição, derivam de impressões simples, que the correspondem e que elas representam com exatidão"22 (HUME, 2000, p28)

Mesmo afirmando a correspondência entre percepções simples e fazendo dessa correspondência um princípio, Hume não esconde que mesmo assim há problemas na relação. Ele cita o exemplo do tom de cor azul. Digamos de um homem que é familiarizado a muitos anos com todas as tonalidades de cor azul com exceção de uma. As tonalidades são colocadas a sua frete em forma crescente e, entre as tonalidades, é colocado um espaço da tonalidade da cor azul que falta. Tal homem seria capaz de construir a ideia da tonalidade da cor azul que falta sem ter tido a impressão que corresponde? Por incrível que possa parecer Hume responde que sim, ameaçando sua própria teoria. E por mais incrível ainda Hume ignora o contra exemplo e segue em frente.

\begin{abstract}
Esse exemplo pode servir como prova de que as ideias simples nem sempre derivam das impressões correspondentes - embora o caso seja tão particular e singular que quase não é digno de nossa atenção, não merecendo que, apenas por sua causa, alteramos nossa máxima geral. (HUME, 2000, p.30)
\end{abstract}

Alguns comentadores de renome não consideram, como Hume o fez, o contraexemplo indigno de atenção. Muito pelo contrário, isso é um problema sério que merecia ênfase e que exigia preocupações por parte de Hume. Antony Flew diz que a simples negação do contraexemplo é escandalosa e que "qualquer generalização é decisivamente falsificada por, até mesmo, um único genuíno contraexemplo" (FLEW, 1986, p21). Bennett, seguindo a mesma linha de pensamento de Flew, diz que "assim que [Hume] admite que a tesa da cópia é 
falsa, e que as ideias podem ser formadas, pelo menos, de uma outra maneira, o jogo acabou" (BENNETT, 2001, vol. II: p.218-219). Stroud, diferentemente de Flew e Bennett, diz que o contraexemplo é apenas hipotético e que "não há sugestão alguma que alguém o tenha, na realidade, visto, ou capaz de ainda vêlo nesta posição" (STROUD, 1977, p.34).

Partindo do pressuposto de o que Hume examina são as operações regulares da mente, tudo que não for regular, contraexemplos raros por exemplo, não são levados em conta 8 . Sendo assim, Hume poderia seguir em frente com sua proposta filosófica. A regularidade dos fatos, dirá Hume, nos mostram que o princípio (impressões simples sempre precedem ideias simples) funciona na esmagadora maioria dos casos. Se quisermos ensinar uma criança a cor azul ou o sabor de algo doce, que lhe mostre a impressão. Tentar instigar a ideia antes de uma impressão seria improvável que funcionasse. Outro caso exemplificado por Hume é de um cego de nascença. Instigar a ideia de cor nele, sem uma impressão também será improvável.

Em suma, o princípio de que a ideia simples é cópia de uma impressão simples é válido, mesmo que os contraexemplos, embora raros, existam. Pois a observação nos revela essa regularidade.

\section{REFERÊNCIAS}

BERKELEY, George. Comentários Filosóficos. São Paulo: Editora UNESP, 2010.

BERKELEY, George. Três diálogos entre Hylas e Philonos. São Paulo: Editora UNESP, 2010.

BERKELEY, George. Tratado sobre os princípios do conhecimento

humano. Editora UNESP, São Paulo. 2010.

BOUCHARDET, Roberta. A imaginação na teoria da mente segundo Hume uma análise a partir do Livro I do Tratado. 2006. 97f. Dissertação (Mestrado Filosofia) - Departamento de Filosofia, Pontifícia Universidade Católica do Rio de Janeiro, Rio de Janeiro, 2006. Disponível em:

$<$ http://www.maxwell.vrac.pucrio.br>

\footnotetext{
${ }^{8} \mathrm{O}$ mais interessante é que quando Hume tratará posteriormente de uma formulação do tipo "o sol não nascerá amanhã”, que é muito menos improvável que a questão da cor azul, o contraexemplo irá valer, enquanto o da tonalidade é descartado.
} 
DELEUZE, Gilles. Empirismo e subjetividade: ensaio sobre a natureza humana segundo Hume. São Paulo: Editora 34, 2001.

DESCARTES, René Regras para direção do espírito. São Paulo: Editora Perspectiva, 2010.

FLEW, A. David Hume: philosopher of moral science. Oxford: Basil Blackwell; Editora Oxford, 1986.

HUME, David. A treatise of human nature. 2. ed. Londres: Penguin Books, 1985.

HUME, David. Investigação sobre o entendimento Humano. São Paulo:

Editora Nova Cultural, 1999.

HUME, David. Sumário do tratado da natureza humana. São Paulo: Editora Companhia, Editora Nacional. 1975.

HUME, David. Tratado da natureza humana. São Paulo: UNESP, 2009.

LOCKE, John. Ensaio sobre o entendimento humano. Lisboa: Editora Calouste, 2010.

SMITH, Plínio Junqueira. O ceticismo de Hume. São Paulo: Editora Loyola, 1995.

STREMINGER, Gerhard. Hume's theory of imagination. Revista Hume Studies, Oxford, v. 6, n.2, p. 91-118, nov. 1980.

STROUD, B. Hume. Londres: Routledge \& Kegam Paul. 1977.

VALADARES, Alexandre Arbex. A teoria da causalidade imaginária na filosofia de Hume. Kriterion: Revista de Filosofia, Belo Horizonte, n. 119, Jun./2009, p. 251-268. Disponível em: <http://www.scielo.br/scielo.php?script>

VERGER, André. David Hume. São Paulo: Editora Edições 70, 1984. 